INTER NATIONAL MONETARY FUND
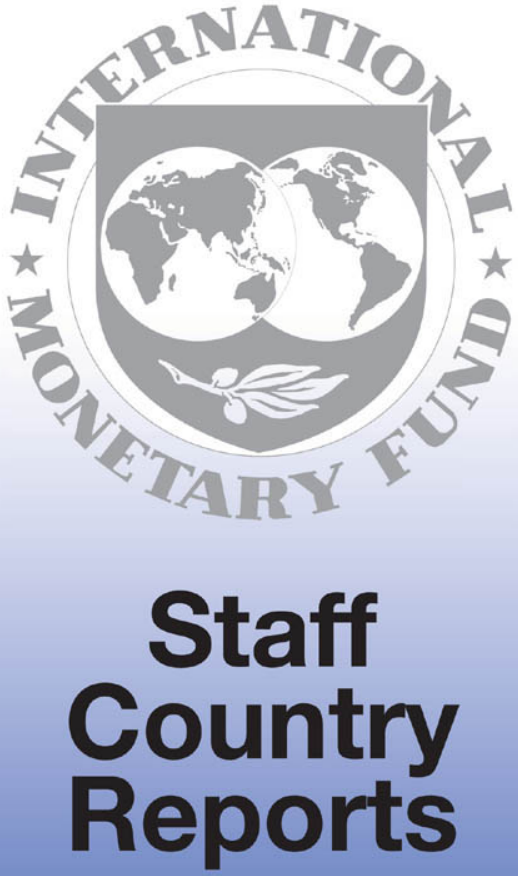


\section{Bangladesh: Joint Staff Advisory Note of the Poverty Reduction Strategy Paper}

The attached Joint Staff Advisory Note (JSAN) of the Poverty Reduction Strategy Paper for Bangladesh, prepared jointly by the staffs of the World Bank and the IMF, was distributed with the member country's Poverty Reduction Strategy Paper (PRSP) to the Executive Boards of the two institutions. The objective of the JSAN is to provide focused, frank, and constructive feedback to the country on its Poverty Reduction Strategy (PRS).

To assist the IMF in evaluating the publication policy, reader comments are invited and may be sent by e-mail to publicationpolicy@imf.org.

Copies of this report are available to the public from

International Monetary Fund • Publication Services

$70019^{\text {th }}$ Street, N.W. • Washington, D.C. 20431

Telephone: (202) 623-7430 • Telefax: (202) 623-7201

E-mail: publications@imf.org • Internet: http://www.imf.org

Price: $\$ 15.00$ a copy

International Monetary Fund

Washington, D.C. 
This page intentionally left blank 


\section{INTERNATIONAL MONETARY FUND \\ AND \\ INTERNATIONAL DEVELOPMENT ASSOCIATION}

\section{BANGLADESH}

\section{Joint Staff Advisory Note on the Poverty Reduction Strategy Paper \\ Prepared by the Staffs of the International Monetary Fund (IMF) and the International Development Association (IDA) \\ Approved by Steven Dunaway and Anthony Boote (IMF) \\ and Praful C. Patel (IDA)}

December 30, 2005

Contents

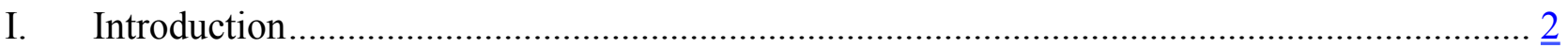

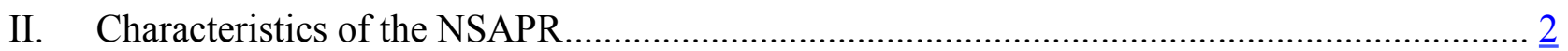

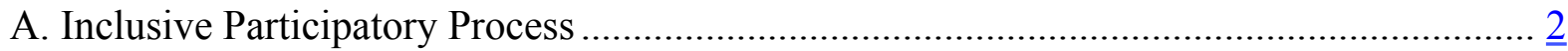

B. Poverty Diagnostics................................................................................................ 2

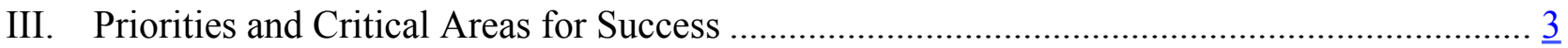

A. Accelerating Pro-poor Growth ................................................................................... $\underline{3}$

B. Promoting Human Development................................................................................. $\underline{8}$

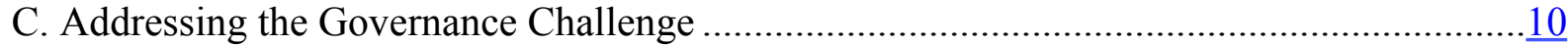

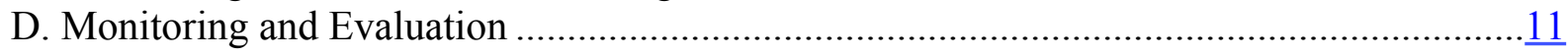

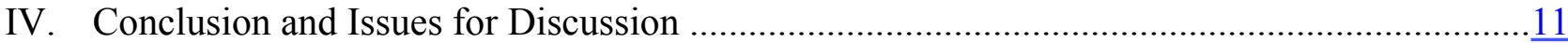




\section{INTRODUCTION}

1. Around independence, Bangladesh was described as the "test case of development." Despite many challenges, its development record thus far has been quite impressive. Overall, the steady improvement in indicators of social and economic well-being gives ground for cautious optimism about the future, though formidable challenges in the areas of human development and governance remain.

\section{The extent and depth of poverty in Bangladesh remains high with half of the} population still living below the poverty line. Therefore, a frontal attack on poverty is a national imperative. Building on the I-PRSP, the Government has articulated its poverty reduction strategy through a full PRSP, titled Unlocking the Potential-National Strategy for Accelerated Poverty Reduction (NSAPR). Espousing a broad definition of poverty, including deprivations in income, food security, quality of life, and vulnerability, the PRSP seeks to address it through a strategically prioritized policy framework that has pro-poor growth, human development, and governance as its main pillars. Overall, the PRSP is an important step towards the achievement of MDG targets for Bangladesh by the year 2015.

3. This Joint Staff Advisory Note (JSAN) provides staffs' advice on key priorities for strengthening Bangladesh's poverty reduction strategy (PRS) and for ensuring its effective implementation. It highlights the key strengths of the PRS while bringing out some weaknesses of existing policies which may undermine successful implementation of the strategy.

\section{Characteristics OF THE NSAPR}

\section{A. Inclusive Participatory Process}

4. To deepen policy ownership, the preparation of the NSAPR included a comprehensive participatory process that involved civil society at the national, regional, and local levels. The NSAPR has benefited from consultations with Members of Parliament, development partners, civil society/academics, NGOs, and people from a wide spectrum of society who were given a chance to provide feedback. The Government has owned the PRS process, welcoming the donors' interest but managing and financing the process almost entirely on its own. The NSAPR gives a fair description of the government's actions to enhance participation, although the staffs recommend that processes to incorporate feedback received be improved with the next review cycle.

\section{B. Poverty Diagnostics}

5. The poverty diagnostics underpinning the NSAPR draws on the latest available surveys supplemented by other qualitative information. Poverty incidence has declined substantially between 1991-92 and 2000, although the extent of the decline differs between 
rural and urban areas. Statistical analysis has shown that characteristics like electricity connection, education, and land and asset ownership are associated with a lower probability of being poor. Most of these correlates have also improved over the decade of the 1990s, which corroborates the decline in consumption poverty. The qualitative insights also suggest improvements, particularly in the incidence of hunger, and some interesting patterns in urbanization, declining importance of land as a source of wealth and power, and deeper penetration of markets. These patterns however need to be substantiated with more representative data for the country. Sectoral analysis of growth and poverty reveals that growth is led by a few dynamic sectors, which has produced higher inequality within and across sectors. The Household Income and Expenditure Surveys (HIES) provide robust and credible data for measuring trends and patterns of consumption poverty. There is a need to agree on a unique methodology for measuring poverty, and to identify the gaps in the availability of data to measure correlates of poverty, insights on which are currently based primarily on qualitative sources.

6. The observed general human and income poverty trends are beyond dispute but greater attention to the causes of human poverty is needed if appropriate policies are to be identified to address these. More broadly, much of the diagnostic analysis should have yielded more specific policy directions. Similarly, the recommendations on addressing inequality are in the right direction, but would benefit from more specificity. Accordingly, staffs recommend that a more focused policy analysis, beyond determinants of poverty and inequality, is conducted for the annual Progress Report. Furthermore, efforts could be made to substantiate qualitative evidence with more systematic analysis based on empirical data.

\section{The NSAPR is correctly anchored in targeting the MDGs as an overall theme.} Bangladesh appears on track to meet most of the MDGs, thanks to the priority given in the budget to delivery of essential services and the space made for non-governmental activity in the sector. As a result, a unique form of NGO-private sector participation has emerged which has allowed the country to be cost-effective in providing education and health services compared to its neighbors. Nevertheless, the NSAPR regards service delivery as one of the major challenges going forward and lays considerable emphasis on improving service delivery.

\section{Priorities And Critical Areas for SuCCeSS}

\section{A. Accelerating Pro-poor Growth}

8. The NSAPR's strategic agenda, built on the policy triangle of pro-poor growth, human development, and governance, is consistent with the challenge of accelerating growth and poverty reduction. Most analysts believe Bangladesh has been underperforming relative to its potential. The strategic agenda in the NSAPR should lead to the right prioritization of policies, but the test of the government's commitment will be in implementation. 


\section{Ensuring macroeconomic stability}

9. The medium-term macroeconomic framework presented in the NSAPR is broadly in line with staff projections under a high growth scenario. Sustained high growth will be necessary to meet the MDG for poverty reduction. However, to achieve such an ambitious target, a steadfast implementation of reform policies presented in the document will be needed, together with favorable economic conditions. As such, it would have been useful to consider alternative macroeconomic scenarios. The staffs thus recommend that future PRS documents include at least two scenarios: a baseline scenario that reflects progress toward agreed objectives but is more in line with past experience, and a more ambitious high-growth scenario. Budgeting the level of expenditure based on a very optimistic outlook could risk losing fiscal discipline in the period ahead unless dramatic improvements in revenue mobilization are recorded.

\section{The staffs welcome the government's commitment to maintain macroeconomic} stability and support the thrust of macroeconomic policies proposed in the NSAPR. Despite a difficult political environment and external shocks, the authorities have generally maintained prudent macroeconomic policies. However, implementation of the strategy outlined in the paper, including funding social expenditures aimed at poverty reduction, without jeopardizing fiscal and debt sustainability will depend crucially on successful efforts to improve revenue collections and to eliminate quasi-fiscal losses currently being recorded in the state enterprise sector. Therefore, the staffs urge the authorities to speed the implementation of the revenue administration measures identified in the NSAPR. In addition to these measures, steps to rationalize the system of tax exemptions and incentives will need to be taken to reduce the associated revenue losses. The emphasis on a monetary policy geared toward price stability and the commitment to market-based instruments are welcome. Low inflation and maintaining policy interest rates that are positive in real terms will also help promote stability of the exchange rate. While the document reaffirms the government's commitment to a flexible exchange rate policy, the staffs also encourage the authorities to further improve the functioning of the foreign exchange market, and to continue to allow the exchange rate to move in response to changes in economic fundamentals.

\section{The government's commitment in the NSAPR to restrain domestic borrowing and rely on concessional external borrowing will contribute to maintaining debt} sustainability. Government debt has remained relatively low and debt service payments have been manageable. However, staffs call for more discussion in future PRS documents of the macroeconomic impact, including on fiscal sustainability, of substantial quasi-fiscal costs associated with the ongoing operating losses in the Nationalized Commercial Banks (NCBs) and the pricing of petroleum and natural gas products. New external borrowing will also need to be carefully screened with any non-concessional loans kept to a minimum. External debt monitoring and management capacity also need to be considerably strengthened to support policy analysis and decision making. 
12. The NSAPR lacks a well thought out process of growth acceleration to justify the high growth projections. Growth prospects continue to be adversely affected by inadequate investment in physical and human capital, infrastructure bottlenecks, and poor governance. The document does not clarify how productivity increases of the magnitude assumed would be achieved. A high growth scenario is plausible only to the extent it is underpinned by policy reforms. Moreover, many potential sources of productivity growth, such as the provision of infrastructure and improvements in labor quality, will take time to materialize.

\section{Successful implementation of the NSAPR will depend on improving the} effectiveness of public expenditure management. The NSAPR rightly identifies freeing the annual development program from the burden of under-completed and under-funded projects as a major challenge. The staffs welcome the emphasis on prioritization in project selection to ensure that there is no case of under-funding leading to delayed implementation. In this regard, the government's commitment to align the NSAPR to a medium-term budgetary framework (MTBF) is a step in the right direction. The government implemented the first phase of a new budget process for four ministries in the FY06 budget and will roll out the new system to six more ministries in the preparation of FY07 budget. The new system encourages allocation of resources for programs integrating recurrent and capital spending and medium-term expenditure plans in line with PRSP priorities, which assures greater funding certainty to priority projects.

\section{A more comprehensive review of the trade policy regime and how it constrains} growth prospects would have been appropriate. While the document stresses the need for ensuring globally competitive industrialization based on the country's comparative advantage, it underplays the role of trade policy in achieving that objective. The document seems ambivalent about the need to act fast in addressing the priority policy and institutional constraints to improving Bangladesh's export competitiveness and diversification. There is little discussion of the fact that the current high trade protection, by creating significant antiexport bias along with a cumbersome import regime, acts as a major drag on export growth. There is also no indication in the NSAPR of the future course to be taken in reforming the highly protective trade regime. It is therefore recommended that future PRS documents develop a medium-term trade reform strategy focusing on nondiscriminatory trade liberalization. In this context, the fiscal strategy would also need to take into account the revenue implications of lower tariffs resulting from further trade reform. The staffs are of the opinion that the NSAPR has not adequately addressed the challenge faced by the RMG industry in the post-MFA era. There is little discussion of existing policy distortions that undermine the sector's competitiveness or the strategic options for addressing them.

\section{Agriculture and rural development}

\section{The NSAPR has identified agriculture and rural development as priority areas}

for rapid poverty reduction in Bangladesh. A comprehensive but very ambitious agriculture and rural development strategy has been outlined. However, job creation, sustained growth, and poverty reduction will depend on broader development of the nonfarm rural sector, a topic which does not receive sufficient attention in the NSAPR. 
16. The main questions that remain to be answered are whether these priorities will be reflected in the annual budgetary allocations; in enforcement of needed policies; in the development of agriculture and rural institutions; in the implementation of agriculture and rural development programs; and in the ownership and action plans of the line ministries. However, given the real resource and capacity constraints and limited coordination and commitment among the line ministries, it will be very difficult to achieve the projected growth rates and poverty reduction goals within the stipulated time frame outlined in the NSAPR document. Furthermore, the document lacks clear prioritization that is so essential to achieve the outcomes within the resource, capacity and governance constrained framework faced by Bangladesh. While the text of the NSAPR document articulates the issues well, the Policy Matrices, which outline the action plans for implementation, are not always consistent with the text and often are rather vague (e.g., Policy Matrix 10 that deals with water resources development and management). Another issue that does not receive adequate attention in the NSAPR is the sustainability of the policies, projects and programs that have been proposed to accelerate growth of agriculture and rural development.

\section{Private sector development}

\section{The staffs applaud the focus of the NSAPR on PSD-driven pro-poor growth} where the primary role of government will be to create an enabling environment, emphasizing SME development and labor-intensive industries. The focus on facilitating fair and competitive business by improving the legal and regulatory environment and implementing an explicit competition policy, with a focus on removing barriers to entry for all enterprises, is very welcome. This will require adequate understanding of competition policy issues and capacity building in government, think-tanks and the private sector.

\section{However, the NSAPR should have given foreign direct investment a higher} prominence, perhaps as one of the key drivers of "improving overall competitiveness." The inability to expeditiously and transparently process large investment proposals from foreign investors has had a bad signaling effect. There is also a need to build adequate technical capacity in government to negotiate with large foreign investors.

\section{The NSAPR's approach to facilitating private sector development includes} direct support to private enterprises. Several types of direct support to private enterprises are mentioned. Staffs believe that use of subsidies makes sense only for promoting change, not maintaining the status quo. Staffs recommend avoiding attempts to promote particular sectors (e.g., in the employment generation/export promotion section, the government identifies 5 sectors to promote) since there are not many examples of such a sector promotion strategy having worked.

\section{The staffs support the emphasis on improving the legal and regulatory} environment for PSD. There is a need to institutionalize the process of regulatory streamlining. Moreover, in addition to streamlining existing procedures, there is a need to subject proposed regulations to rigorous scrutiny, using tools, such as regulatory impact 
assessments, which look at the costs and benefits of regulations. Some bold, in-depth, regulatory reforms can be piloted in some areas, such as special economic zones, and then replicated elsewhere.

\section{While the NSAPR recognizes the need to implement NCB reforms speedily to} support investment and growth, it does not reflect the Government's own roadmap for financial sector reforms. The roadmap, implementation of which has already begun, includes, among others, a time-bound action plan for the corporatization and eventual privatization of the NCBs, and the strengthening of Bangladesh Bank with full authority and autonomy to supervise the entire banking system and conduct monetary policy independently. The staffs thus recommend that future PRS documents incorporate the government's banking sector reform program. Further, the NSAPR omits a discussion of the other important facets of the financial sector, such as capital markets and contractual savings institutions, which are currently fairly underdeveloped. The NSAPR rightly emphasizes upscaling micro-credit - an especially successful enterprise in Bangladesh reaching about 20 million poor people - and enhancing its poverty impact. The need to strengthen the legal and regulatory framework for the micro-credit sector to further strengthen its performance is aptly noted in the NSAPR; some recent initiatives by the government in this area are encouraging. The challenge of addressing the "missing middle"--micro and small enterprises excluded both by micro-credit institutions and the formal banking sector--is a particularly relevant one but without any easy or obvious solutions. Policymakers need to continue seeking appropriate and innovative solutions in close consultations with micro-credit institutions and other relevant stakeholders.

\section{Infrastructure and urban development}

\section{The World Bank's Investment Climate Assessment (ICA) for Bangladesh has} identified infrastructure as the top constraint to business investment. The NSAPR fully endorses the pivotal role of infrastructure for growth and poverty reduction and gives a fair analysis of sector deficiencies, with an adequate focus on urban rural linkages. However, in the transport section, discussion of the National Land Transport Policy (NLTP) — which spells out all of the key priorities in the sector including its direct impact on poverty alleviation - is conspicuously absent. The power sector strategy needs greater focus on governance improvements in BPDB, DESA, and the PBSs, and most importantly setting a generation framework providing for least cost planning, transparent procurement processes, and support to attract private investors. Management of Bangladesh's important natural gas resources also needs further consideration. The analysis would also be enhanced by a reassessment of the optimal allocation of medium-term resources across sectors, with a better account of the powerful pro-poor potential in some sectors (for instance, urban traffic management, inland water transport and high-capacity urban public transport).

23. The power sector analysis contemplates significant restructuring of the utilities, which is indeed strongly needed to improve their finances and attract investors, all with a view to increasing service delivery to the poor. However, it might be useful to give further thought to the proposed restructuring strategy by reviewing governance arrangements 
to allow more independence of entities currently part of BPDB and of PBSs; taking a much stronger approach to addressing DESA's contribution to the quasi-fiscal deficit; and, finally and most importantly, setting a generation framework providing for least cost planning, transparent procurement processes and support to attract private investors.

\section{The staffs agree with the NSAPR's assessment about the worsening state of the} urban poor, who face a lack of land, housing, and access to sanitation, insufficient infrastructure services, and growing inequality. But, more importantly, the deteriorating urban conditions do not receive enough emphasis, despite the significant growth of the urban population and its contribution to the country's economy. Recognition of water and sanitation as one of the priorities of the strategy is welcome. The strategy would benefit from a more concrete review of the critical reforms needed to improve urban services delivery, including local government, corporate and non governmental options, within costs compatible with a realistic medium-term fiscal framework. This would entail better performance monitoring, cost recovery targets and needed reforms in urban management, such as land use.

\section{B. Promoting Human Development}

\section{The NSAPR's focus on human development as one of the three strategic pillars} of the PRS is appropriate and targeted goals are consistent with the achievement of the MDGs. The main challenge will come from institutional issues. These range from the division of the education sector between two different ministries which are not well coordinated, the overly centralized system of health service delivery, and the fragmented social safety net. The NSAPR rightly focuses on issues such as education quality and internal efficiency of the system, and access to education and health services for the poor. It also notes that improvement of human development and health can be a major factor in the reduction of poverty and deprivation, providing the poor with the tools to access the benefits of growth. The plan proposed for social protection is also very appropriate for the country's needs. The NSAPR's weakness lies in the costing which leaves out large and expensive items, for example secondary and post-secondary education. It also does not address the risks arising from the lack of effective coordination between separate Ministries of Primary and Secondary Education, the high overheads arising from multiple overlapping programs run by multiple Ministries, or the centralized model of service delivery in health care.

\section{The emphasis on strategic collaboration between the government and NGOs in} order to achieve the MDG target of universal access in primary education is welcome. In secondary education, many of the recommendations are consistent with improving quality and access. The NSAPR highlights MoE's key reform agenda which includes a strategy to prevent 'elite capture' of SMCs by empowering them to reduce political influence in their composition; setting up of the Teacher Registration and Certification Authority; and linking financing of institutions to performance. There is also discussion of targeting the stipend program to the poorest and bringing the madrasah curriculum more in line with the general curriculum -something that was not on the table even a couple of years ago. The plan to shift operational decision making to the district and upazilas is appropriate. However, some more 
elaboration on how this shift to greater 'local governance' is envisaged would be useful, especially in light of the weak capacity at lower levels of government.

\section{The strategic focus is also appropriate in higher and vocational/technical} education (TVET). The plans being proposed are all appropriate and will lead to a more demand-driven, efficient and cost-effective system. Hence, there is no need to impose a percentage target for the number of individuals entering the vocational streams. The strategic approach in higher education makes economic sense; what is needed, however, is to back this up with a costing exercise for this and for TVET.

\section{The health, nutrition and population (HNP) goals are closely linked to the}

MDGs. Bangladesh is well on its way to achieving these goals, except for maternal health. The focus on malnutrition and addressing it in a multisectoral approach is amply justified. The country may well be on its way to achieving the MDG of halving malnutrition between 1990 and 2015, though current levels of malnutrition — amongst the highest in the world - are still a severe handicap in the race for faster human capital formation. The emphasis on paying attention to closely related areas, such as food security, food safety, water and sanitation, commerce, trade, agriculture, early childhood development, disaster management etc., in a more integrated manner is appreciated and such a multi-sectoral approach makes target achievements more likely. An area of weakness is the lack of explicit recommendations and strategies with respect to $\mathrm{NGO}$ /private service delivery diversification, health governance and targeting schemes. The absence of performance indicators from the policy matrix is also a notable omission.

29. The NSAPR document does a good job in summarizing the key social safety net programs in Bangladesh, discussing the impacts (while acknowledging the lack of rigorous evaluations of these programs), and then highlighting the key weaknesses in these programs. We are also in general agreement with most of the actions proposed in the NSAPR and would support making greater coordination among government and nongovernment agencies in the design and implementation of these programs a high priority. Also, the proposal to evaluate programs is very welcome. One would have liked to see some more discussion of targeting - especially the use of proxy means testing to better target beneficiaries of safety net programs.

30. Cognizant of the fact that women are a disadvantaged and vulnerable group, the NSAPR gives high priority to women's advancement and empowerment as critical for poverty reduction and sustainable development. The staffs welcome this approach to ensuring social inclusion and empowerment of women in order to create equality of opportunities on the path to social and economic development.

31. The NSAPR does a good job of establishing the poverty-environment linkage and appropriately stresses improved management of natural resources and the environment as critical for sustainable development. In this light, the attention to conservation and regeneration of natural resources is welcome. Staffs recommend that annual 
Progress Reports contain adequate reflection of environmental management actions taken by the Government.

\section{Addressing the Governance Challenge}

32. Given that Bangladesh suffers from a poor reputation for governance, the strong focus on governance in the NSAPR is very welcome. Bangladesh has achieved many notable successes in the economic and social well-being of its people. That many of those successes have been achieved despite poor governance suggests that with better governance Bangladesh's performance would come closer to the rates of economic growth and poverty reduction that are required to meet the PRS's goals. Consistent with the advice of the NSAPR, the government needs to strategically target key areas and initiate governance reforms in a manner that send powerful signals of the seriousness of its intent to address these issues. The strategic and selective approach taken in the NSAPR for addressing governance issues is encouraging. However, the lack of specificity on sectoral governance reforms suggests that ownership needs to be broadened within the government. While recognizing the need for broad-based governance reforms ranging from the judiciary to anticorruption to decentralization, the NSAPR's strategic focus is on those governance issues that are of most concern to the poor (delivery of essential services and personal security).

\section{The NSAPR acknowledges that the quality of political competition in}

Bangladesh contributes to the high levels of corruption and calls for strengthening and enforcing the codes of conduct within the electoral process. The NSAPR stresses the risk that reform priorities are likely to vary between different political, social and economic groups and that these differences need to be resolved constructively within a broad national consensus, particularly if the thrust of reforms is to be maintained by different governments over time. However, while the document points to a decline in the quality of policy engagement between politicians and the public administration, it offers few suggestions for improvement.

\section{The NSAPR correctly emphasizes the importance of improvements in public} financial management as a means to reduce corruption and improve service delivery to the poor. The focus is largely on procurement, which is undoubtedly the most important source of budgetary leakages. However, the government also needs to develop a time-bound public financial management program that systematically improves the quality of its internal financial controls, asset inventories, accounting and audit processes and strengthens the quality and integrity of personnel responsible for managing the key budget processes. Such a program would contribute to achieving visible progress in the country's financial management.

35. The NSAPR rightly recognizes the importance of improving governance at the sectoral level, particularly in those sectors that have the highest impact on growth and poverty reduction such as infrastructure, communications, health, education, disaster management, local governance and land. However, the government needs to address the lack of transparency and accountability in the private and public provision of infrastructure, 
particularly power and ports, the two most important bottlenecks to growth in the economy, and to increasing the level of foreign direct investment. It also needs to address other serious impediments investors face including the weak and deteriorating regulatory framework and a corrupt and weak tax administration. The investment and growth that such reforms will unleash will create the employment and poverty reduction that will be of greatest significance to the poor.

\section{Monitoring and Evaluation}

36. For the NSAPR to be a credible instrument for accelerating growth and poverty reduction in Bangladesh, effective implementation, supported by a rigorous monitoring and evaluation regime, is going to be the key to success in achieving its goals. For effective implementation, it is also critical to prioritize programs and stay focused on the essentials. The NSAPR summarizes the efforts underway, including data sources, to track long-term MDG-related indicators, as well as the intermediate indicators in the context of poverty monitoring. Furthermore, there is also a proposal to include an "MDG module" in the HIES. However, with the exception of the HIES, the frequency, regularity and the implementing agencies for the surveys and data gaps are not clarified. Staffs recommend that a systematic stocktaking of data sources, with a clear consensus on indicators to monitor, be undertaken to ascertain the need for an expanded HIES and the capacity of BBS to carry out such expansion. Two sets of poverty trends are reported in the NSAPR, using two alternate methodologies, which creates difficulties in assessing trends in poverty and the impact of policy. Staffs recommend that a consensus be reached on a single methodology before the analysis of the upcoming HIES (2006).

37. The exclusive reliance on concerned ministries for data on inputs and outputs can be misleading and inadequate. For this to work the relevant monitoring systems in ministries would need to be evaluated and improved. In addition, third-party validation may be necessary, particularly to monitor outputs. The gaps in both the data collection systems for monitoring and the institutional arrangements suggest the need for a concerted effort to rationalize needs with sources and identify the capacity requirements for institutions like BBS to deliver quality data in a timely manner. Since the institutional focus is on a single nodal agency, the mechanisms for policy feedback are unclear. Staffs recommend that a comprehensive monitoring and evaluation framework and implementation plan be developed in the annual Progress Report.

\section{CONCLUSION AND ISSUES FOR DiSCUSSION}

38. On balance the staffs of the World Bank and the IMF believe that the poverty reduction strategy outlined in the NSAPR is comprehensive and contains critical policy actions that, over time, could help foster accelerated growth and poverty reduction. In particular, the poverty diagnostics contained in the NSAPR are of high quality as they come to grips with the multi-dimensional nature of poverty, recognizing both income and human dimensions, in making judgments on poverty trends and prospects. 


\section{At the same time, the staffs point to considerable risks to successful} implementation of the NSAPR. First, there is the political risk emerging from confrontational politics. Second, though a sustainable institutional foundation has been laid for carrying the strategy forward, and a mechanism for inter-ministerial partnership has been built into the process, severe capacity constraints and lack of incentives in the civil service could impede any tangible progress. Finally, the biggest implementation risk is often the lack of a concrete strategy "backed" by adequate resources. However, the MTBF, which is aligned to the NSAPR, is under implementation in ten ministries. Experience shows that countries that are in gear with MTBF have predictable plans and resources to move the PRSP agenda forward.

40. Do Executive Directors concur with: (i) the broad direction of the proposed strategy as outlined in the NSAPR's strategic agenda built on the policy triangle of pro-poor growth, human development and governance and its implementation; (ii) priority areas identified by the staffs for strengthening the poverty reduction strategy and its implementation; and (iii) staffs' characterization of implementation risks? 